\title{
CHRISTOPHE CHAZALON, Les Icones de Théodore de Bèze (1580) entre mémoire et propagande
}

\section{Filippo Fonio}

\section{(2) OpenEdition}

\section{Journals}

\section{Edizione digitale}

URL: http://journals.openedition.org/studifrancesi/33016

DOI: 10.4000/studifrancesi.33016

ISSN: 2421-5856

\section{Editore}

Rosenberg \& Sellier

\section{Edizione cartacea}

Data di pubblicazione: 1 décembre 2005

Paginazione: 627

ISSN: 0039-2944

\section{Notizia bibliografica digitale}

Filippo Fonio, «Christophe chaZalon, Les Icones de Théodore de Bèze (1580) entre mémoire et propagande», Studi Francesi [Online], 147 (XLX | III) | 2005, online dal 01 novembre 2015, consultato il 20 avril 2021. URL: http://journals.openedition.org/studifrancesi/33016 ; DOI: https://doi.org/10.4000/studifrancesi. 33016

Questo documento è stato generato automaticamente il 20 avril 2021.

\section{(c) (i) (9)}

Studi Francesi è distribuita con Licenza Creative Commons Attribuzione - Non commerciale - Non opere derivate 4.0 Internazionale. 


\title{
CHRISTOPHE CHAZALON, Les Icones de Théodore de Bèze (1580) entre mémoire et propagande
}

\author{
Filippo Fonio
}

\section{NOTIZIA}

CHRISTOPHE CHAZALON, Les Icones de Théodore de Bèze (1580) entre mémoire et propagande, «Bibliothèque d'Humanisme et Renaissance», LXVI, 2 (2004), pp. 359-376.

1 Le Icones di Théodore de Bèze, edite in latino nel 1580 e tradotte in francese da Simon Goulart l'anno seguente, sono da ricondurre alla tradizione dei ritratti di uomini illustri. Il genere in questione, ereditato dall'Antichità (Plutarco, Svetonio, Plinio il Vecchio, Valerio Massimo fra gli altri), conosce una certa fortuna in età rinascimentale, in particolare attraverso la diffusione delle Vite di Vasari e del Museo di Giovio. Lo studioso ridimensiona nondimeno l'importanza di tali modelli rispetto al progetto e alla realizzazione della galleria di Théodore de Bèze, circostanziando l'iniziativa del successore di Jean Calvin sulla base degli avvenimenti che interessano in quegli anni la storia delle comunità riformate. Proponendo una lettura lineare delle Icones (pratica quantomeno eterodossa per un genere a organizzazione tematica come il de viris illustribus), Chazalon individua una serie di elementi interpretabili come tracce di una precisa volontà di natura politico-confessionale, tanto nella scelta delle personalità da includere nella compilazione, quanto nella successione dei ritratti. Alla base delle scelte di Bèze sarebbe un intento encomiastico nei confronti della Riforma tutta, non esente da una rivendicazione del primato morale dei calvinisti. Le Icones fungerebbero dunque da monumento in onore dei martiri della Riforma, non soltanto da intendersi in senso stretto come i morti in seguito alla persecuzione papista, ma piuttosto a partire dai precursori per giungere a figure autorevoli sentite come affini alla sensibilità 
riformata, Erasmo ad esempio. La galleria rappresenta al contempo una raccolta di exempla, a uso dei posteri come dei contemporanei. 